\title{
Fish-isolated strains of Hartmannella vermiformis Page, 1967: morphology, phylogeny and molecular diagnosis of the species in tissue lesions
}

\author{
Iva Dyková ${ }^{1,2}$, Zuzana Pindová $^{2}$, Ivan Fiala $^{1,2}$, Helena Dvořáková $^{1}$ and Blanka Macháčková ${ }^{1}$ \\ ${ }^{1}$ Institute of Parasitology, Academy of Sciences of the Czech Republic, Branišovská 31, 37005 České Budějovice, Czech \\ Republic; \\ ${ }^{2}$ Faculty of Biological Sciences, University of South Bohemia, Branišovská 31, 37005 České Budějovice, Czech Republic
}

Key words: amphizoic amoebae, Hartmannella vermiformis, morphology, phylogeny, in situ hybridisation

\begin{abstract}
Based on morphological and molecular characterisation, four amoeba strains isolated from organs of freshwater fish were identified as Hartmannella vermiformis Page, 1967. Small subunit rRNA gene sequences of these strains expand the set of corresponding complete and almost complete sequences of this species to twelve. A new species-specific oligonucleotide probe inferred from recently available SSU rRNA gene sequences was designed and successfully tested in tissue lesions produced by one strain of $H$. vermiformis in experimentally infected fish.
\end{abstract}

In recent years, the importance of free-living amoebae of the genus Hartmannella Page, 1967 has been increasingly recognized in association with human diseases. Contrary to Acanthamoeba spp., Naegleria fowleri, Balamuthia mandrillaris and Sappinia diploidea known as primary agents of human diseases, opinion is divided on the pathogenicity of Hartmannella species (Aitken et al. 1996, Inoue et al. 1998, De Jonckheere and Brown 1998, 1999, Kinnear 2003). The data collected on a variety of bacterial endocytobionts in Hartmannella vermiformis Page, 1967, and the recognition of its special role in the propagation of Legionnaires' disease, provide evidence that these amoebae are more important as hosts of true or potential pathogens of humans than as primary agents of human diseases (Fields et al. 1989, Kuchta et al. 1993, Brieland et al. 1996, Fields 1996, Horn et al. 2000). Scarce data available on Hartmannella infections in animals including fish point to a similar situation (Kadlec 1978, Bomhard et al. 2002, Telford and Bursey 2003, Dyková and Lom 2004). Nevertheless, pathogenicity of Hartmannella spp. for aquatic organisms cannot be excluded. The presence of Hartmannella trophozoites in water column and sediments was mentioned in a series of surveys (Smirnov and Goodkov 1995, Smirnov 1996/1997, 2002, Ettinger et al. 2002), but natural infections of freshwater fishes were rarely reported and diagnosis of one isolated strain was based solely on the morphology of its trophic and cyst stages (Dyková et al. 1997). To extend our knowledge on Hartmannella spp., four fishisolated strains are presented in this study. In addition to their morphological and molecular characterisation, the design of an oligonucleotide probe for direct diagnosis of $H$. vermiformis forms part of the study.

\section{MATERIALS AND METHODS}

A combination of morphological, molecular and phylogenetic methods was used to characterise four non-vahlkampfiid "limax" amoebae isolated from organs of fish. Clonal cultures of fish-isolated strains are cryopreserved and stored in the culture collection of the Institute of Parasitology, Academy of Sciences of the Czech Republic, České Budějovice.

\section{Strain origin, culturing and morphological studies}

The host and local origin of fish-isolated strains are listed in Table 1. Non-nutrient agar (NNA) was used for primary isolations and for a long period of subculturing. Unidentified bacteria brought by individual strain populations to cultures were gradually substituted with autoclaved suspensions of Escherichia coli, Bacillus subtilis or Pseudomonas sp., seeded on NNA enriched with malt and yeast extracts $(0.1 \mathrm{~g}$ of each per litre). Clonal cultures of individual strains (maintained at $20^{\circ} \mathrm{C}$ and subcultured once a week) were used for light microscopical and ultrastructural observations as well as DNA extraction. Hanging drop preparations and standard light microscopical approaches, including translucent light and Nomarski differential interference contrast (DIC), were used to characterise and document morphological features of living amoebae. Fixation for electron microscopy was done in situ on agar plates using cacodylate buffered $2.5 \%$ glutaraldehyde, followed by postfixation with $1 \%$ osmium tetroxide (Dykstra 1993). Spurr's resin was used for embedding of peletted cells. The ultrathin sections were double stained with uranyl acetate and lead citrate and examined under a JEOL JEM 1010 electron microscope.

\section{Molecular characterisation of strains under study}

The small subunit ribosomal RNA gene was used as a molecular marker. Genomic DNA was extracted from clonal cultures of trophozoites using the DNeasy ${ }^{\mathrm{TM}}$ Tissue Kit (Qiagen, Germany) according to the manufacturer's protocol.

Address for correspondence: I. Dyková, Institute of Parasitology Academy of Sciences of the Czech Republic, Branišovská 31 , 370 05 České Budějovice, Czech Republic. Phone: ++420 387775 423; Fax: ++420 385310 388; E-mail: iva@paru.cas.cz 
Table 1. Hartmannella strains included in the study. (Fish hosts collected in water bodies in the Czech Republic.)

\begin{tabular}{|l|l|l|}
\hline Clone & Host / organ / local origin & Strain isolated / cloned \\
\hline PFG/I & Perca fluviatilis Linnaeus, 1758 / gills / Dubný pond & Nov 2000 / Jan 2001 \\
TN102/I & Oreochromis niloticus (Linnaeus, 1758) / kidney / Tisová farm* & Jun 1994 / March 1995 \\
4480/I & Cyprinus carpio Linnaeus, 1758 / spleen / Vodňany pond & Dec 1990 / March 2002 \\
4391/I & Tinca tinca (Linnaeus, 1758) / liver / Lužnice River & Oct 1990 / Nov 1997 \\
\hline
\end{tabular}

*mixture of riverine and thermally polluted water

The SSU rRNA gene was amplified using PCR. Each PCR reaction mix contained $1 \mu 1$ DNA sample, $2.5 \mu 110 \times$ buffer (Promega), $2 \mu \mathrm{l} 2.5 \mathrm{mM}$ dNTP, $1 \mathrm{U}$ Taq DNA polymerase (TaKaRa), 10 pmol of each primer (forward ERIB1 5'ACCTGGTTGATCCTGCCAG-3' and reverse ERIB10 5'CTTCCGCTGGTTCACCTACGG-3') (Barta et al. 1997) and sterile distilled water added to a final volume of $25 \mu$ l. Cycling was carried out in a T3 thermocycler (Biometra). The reaction mixture was preheated $5 \mathrm{~min}$ at $95^{\circ} \mathrm{C}$. The amplification was carried out for 30 cycles $\left(95^{\circ} \mathrm{C} / 1 \mathrm{~min}, 44^{\circ} \mathrm{C} / 1.5 \mathrm{~min}\right.$ and $72^{\circ} \mathrm{C} / 1.5 \mathrm{~min}$ ) followed by a final extension at $72^{\circ} \mathrm{C} / 10 \mathrm{~min}$. Amplicons were gel-purified and cloned into $\mathrm{pCR}^{\circledR} 2.1 \mathrm{TOPO}$ cloning vectors (Invitrogen) using the suggested protocol. Plasmid DNA was purified using the QIAprep Spin Miniprep Kit (Qiagen). Sequencing was accomplished in both directions using the CEQ DTCS Dye Kit (Beckman Coulter) with a combination of flanking and internal primers on an automatic sequencer $\mathrm{CEQ}^{\mathrm{TM}} 2000$ (Beckman Coulter).

Newly acquired complete SSU rRNA gene sequences of fish-isolated strains were aligned together with 22 sequences retrieved from the GenBank database. This set consisted of 8 complete and 6 partial SSU rRNA gene sequences from strains designated as $H$. vermiformis, two sequences of Hartmannella sp. strains isolated from tadpoles, one sequence each of $H$. cantabrigiensis, Echinamoeba exundans, Saccamoeba limax and Glaeseria mira. Vannella anglica and Platyamoeba placida were used as an outgroup. Alignment was done using the Clustal_X program (Thompson et al. 1997) with various alignment parameters. The BioEdit program (Hall 1999) was used for visual control of alignment. To infer phylogenetic trees, the maximum parsimony (MP) and maximum likelihood (ML) methods were used as implemented in the program package PAUP*, version 4.0b8 (Swofford 1999). MP analysis was done using a heuristic search with random addition of taxa (10 replications). Gaps were treated as missing data. MP analyses were performed using three transition:transversion (Ts:Tv) ratios $(1: 1,1: 2$, and 1:3). The strict consensus tree was made from the resulting topologies. For ML analysis, the likelihood ratio test (LRT) implemented in Modeltest v. 3.06 (Posada and Crandall 1998) was used to determine the best model of evolution. Based on LRT, the ML analysis was performed with the GTR $+\Gamma$ model of evolution ( $\alpha$ shape parameter was 0.4557$)$. Clade support was assessed with bootstrapping of 1,000 replicates.

\section{Oligonucleotide probe and fluorescence in situ hybridisation}

Design and labeling of probe. Comparative analysis of twelve complete SSU rRNA gene sequences of strains diagnosed (in agreement with their morphological and molecular characterisation) as belonging to $H$. vermiformis, with representatives of all relevant groups of eukaryotic organisms, was performed to identify target sequences of appropriate specificity. The uniqueness of the selected sequence was tested using the Blast Search of the NCBI database. The oligonucleotide probe complementary to the $H$. vermiformis specific sequence was designed as follows: 5'-ATC CGC GAG GGT GGG GAA TCA ACG G-3'. It was synthesized by Generi Biotech (Czech Republic) and labeled with digoxigenin using the DIG Oligonucleotide Tailing Kit (Roche). The labeled probe was stored at $-20^{\circ} \mathrm{C}$.

Target cells. Trophozoites of clonal cultures of three $H$. vermiformis strains under study $(4380,4391, \mathrm{PFG})$ removed from agar plates by washing with Page saline and attached to poly L-lysin- or silan-coated slides and trophozoites of $H$. vermiformis (strain TN102) in histological sections of experimentally infected tilapias Oreochromis niloticus. Trophozoites of Acanthamoeba sp. (fish-isolated strain P121) and Saccamoeba sp. (fish-isolated strain LOS7N) attached to slides were used as negative controls for the in situ hybridisation.

Hybridisation experiments and detection of hybridisation. To ensure efficient complementary base pairing between the labeled probe and targets, basic steps of methodology described by Young (1994) and Komminoth (1996) were applied in this study. In the course of replicated hybridisation experiments, the original methodology was slightly modified. The hybridisation solution contained $60 \%(\mathrm{v} / \mathrm{v})$ of formamide and the temperature for hybridisation reaction was set at $39^{\circ} \mathrm{C}$. Each hybridisation was carried out on microscopic slides to which $30 \mu \mathrm{l}$ hybridisation solution containing $5 \mathrm{ng} / \mu \mathrm{l}$ of specific probe was added. The detection of hybridisation was done using anti-DIG antibody with conjugated fluorescein (Roche). When hybridisation was completed, sections were mounted with antifadent mounting medium (Traut et al. 1999). A cover slip was sealed to the slide using clear nail-varnish to retard evaporation.

Documentation. Black and white micrographs were taken with an Olympus DP70 CCD camera connected to an Olympus BX51 microscope. False colouring was done using the GIMP 2.0 program (www.gimp.org), which calculated fluorescence signal ratios and accordingly assigned to black and white images the corresponding intensity of fluorescence colour.

\section{RESULTS}

\section{Identification of strains under study}

Light microscopy of non-vahlkampfiid "limax" amoebae included in the study exhibited uniform morphological features consistent with those described by Page (1967) in H. vermiformis. Elongate cylindrical locomotive forms of monopodial trophozoites were the most common when observed in hanging drop 


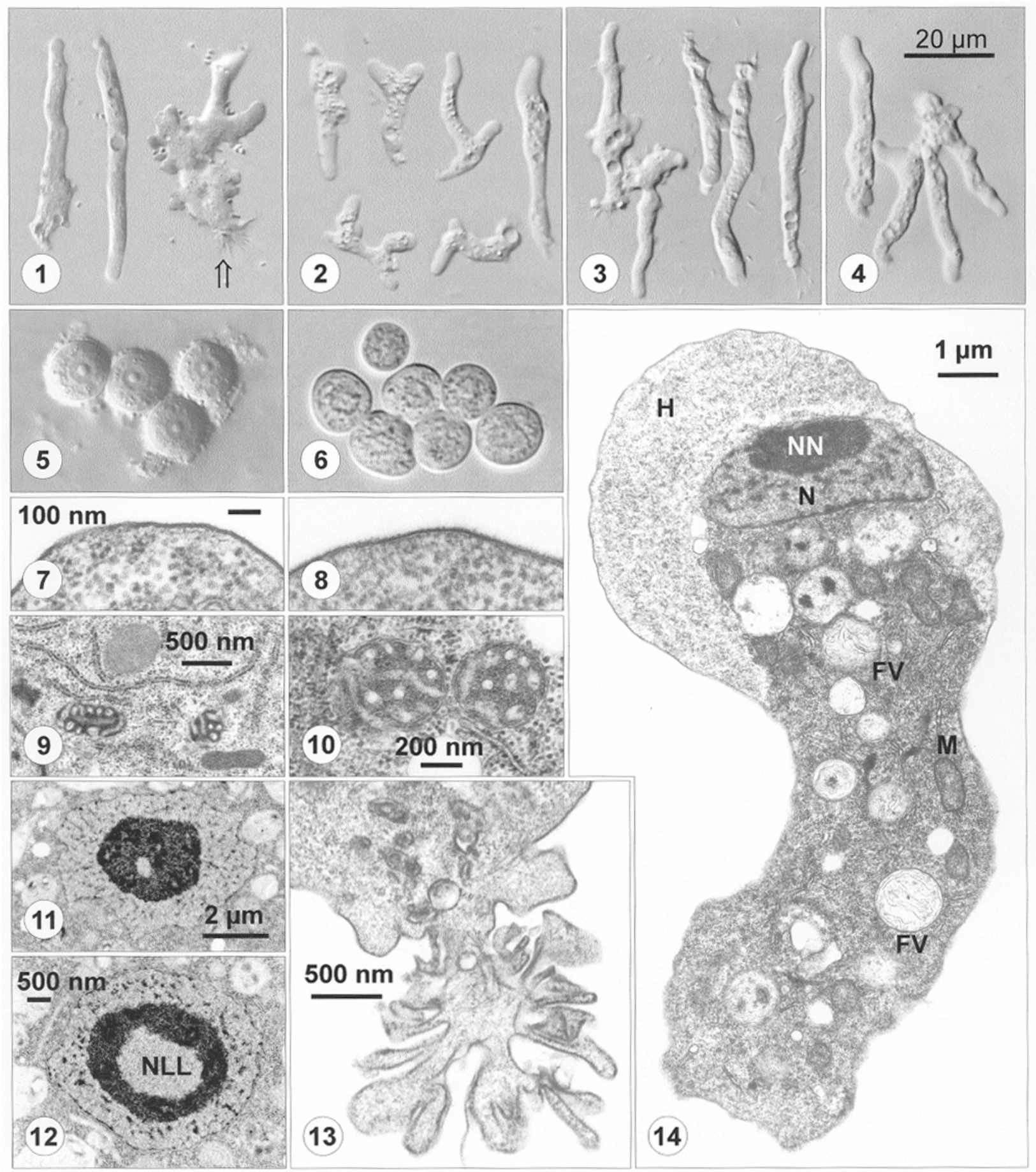

Figs. 1-14. Light microscopy and ultrastructure of fish-isolated Hartmannella vermiformis strains. Figs. 1-4. Trophozoites from clonal cultures of strains under study in the following order: 4391, 4480, TN102 and PFG. Arrow marks uroidal filaments. Fig. 5. Young cysts of strain 4480. Fig. 6. Mature cysts of strain TN102. Figs. 7, 8. Fine structure of the cell surface of trophozoites (Fig. 7. - strain 4391, Fig. 8. - strain TN102). Fig. 9. Granular endoplasmic reticulum and mitochondria in the cytoplasm of a trophozoite (strain 4391). Fig. 10. Mitochondria with tubular cristae as seen in a trophozoite of strain 4391. Figs. 11, 12. Examples of the fine structure of nuclei in trophozoites of strain 4480. NLL - nucleolar lacuna. Fig. 13. Posterior part of a trophozoite (strain PFG) with a well-developed uroid. Fig. 14. Anterior part of locomotive form (overview, trophozoite of PFG strain). FV food vacuoles with remnants of phagocytosed material; $\mathrm{H}$ - hyaloplasm; $\mathrm{M}$ - mitochondria; $\mathrm{N}$ - nucleus; NN - nucleolus. Figs. $1-6,7+8$, same magnification. 


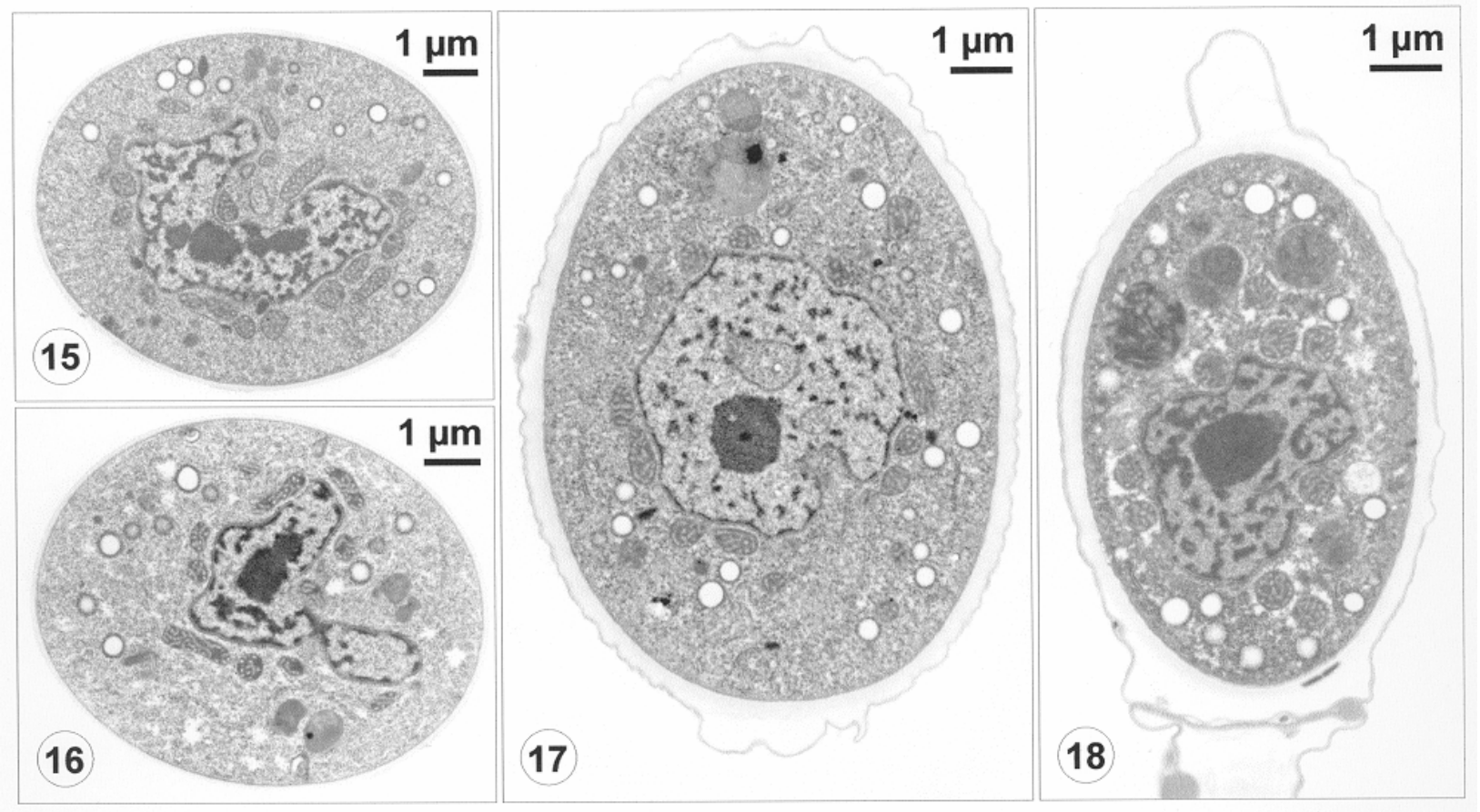

Figs. 15-18. Cysts of fish-isolated Hartmannella vermiformis strains. Figs. 15, 16. Young cysts with lobed nuclei and closely apposed wall (4480/I). Figs. 17, 18. Cysts of the same clonal culture (4480/I) with partly (Fig. 17) and distinctly (Fig. 18) separated outer and inner layers.

preparations. They had a hyaline anterior region almost always longer than broad. A lateral protrusion of pseudopodia occurred when the locomotive form changed direction of movement (Figs. 1-4). When standard procedures were applied, trophozoites of irregular shape were rarely observed. Posterior uroidal filaments and the bacteria adhering to them were observed in less active and well attached trophozoites (Figs. 1, 13). Contractile vacuoles (sometimes more numerous) and the position of the nucleus were easily discernible in Nomarski DIC. All strains under study formed smoothwalled cysts, which were spherical or ovoid (Figs. 5, 6). The length range of straight locomotive forms was 28$42 \mu \mathrm{m}$ and the median of cyst diameter was $8.7 \mu \mathrm{m}$.

With the exception of the cell surface, the other details of ultrastructure observed in strains under study basically fit to the original description of $H$. vermiformis fine structure by Page (1985). In contrast with electron micrographs included in the comparative study of "limax" amoebae (Page 1985), the surface of Hartmannella trophozoites of fish-isolated strains was not differentiated. The "sucker" or "cup-like" structures were not observed (Figs. 7, 8). Also, the nuclear envelopes in trophozoites and cysts of fish strains were almost smooth, lacking the folds demonstrated in the electron micrographs of the study by Page (1985). The electron microscopic images of nuclei varied in the size and shape of nucleolus as well as the proportion and distribution of the low-density nuclear matrix and dense granular areas of stainable chromatin (Figs. 11, 12). The mitochondria contained tubular cristae of uniform di- ameter. The profiles of cristae seen in ultrathin sections indicated their random interlacing rather than branching (Figs. 9, 10). In the well-stained cytoplasm, cisternae of granular endoplasmic reticulum were conspicuous due to electron-dense ribosomes closely associated with their membranes (Fig. 9). Cyst walls were mostly homogeneous, their thickness being related to the age of cysts. While elongate lobed nuclei prevailed during cyst formation, nuclei of mature cysts were rather spherical. Cyst mitochondria were located in close proximity to the nuclei (Figs. 15-18). The thin electron-dense outer layer was sometimes slightly separated from the cyst wall (Figs. 17, 18), which was not strain related. More pronounced and more frequent separation of the corresponding outermost layer of the cyst wall was observed when the structure and electron density indicated that the cyst was no more viable.

Due to similarities in descriptions of Hartmannella species, fish-isolated strains were tentatively identified as $H$. vermiformis in the morphological phase of the study. A molecular marker was used to verify this diagnosis.

\section{Sequence data and phylogenetic analysis}

The complete nucleotide sequences of the SSU rRNA gene obtained in this study for four fish-isolated Hartmannella strains are available in the GenBank under the accession numbers DQ084363 (4480), DQ084364 (4391), DQ084365 (TN102) and DQ084366 (PFG). These sequences are 1832-1835 bp, showing 99.30$99.95 \%$ mutual identity. The percentage of sequence 
B

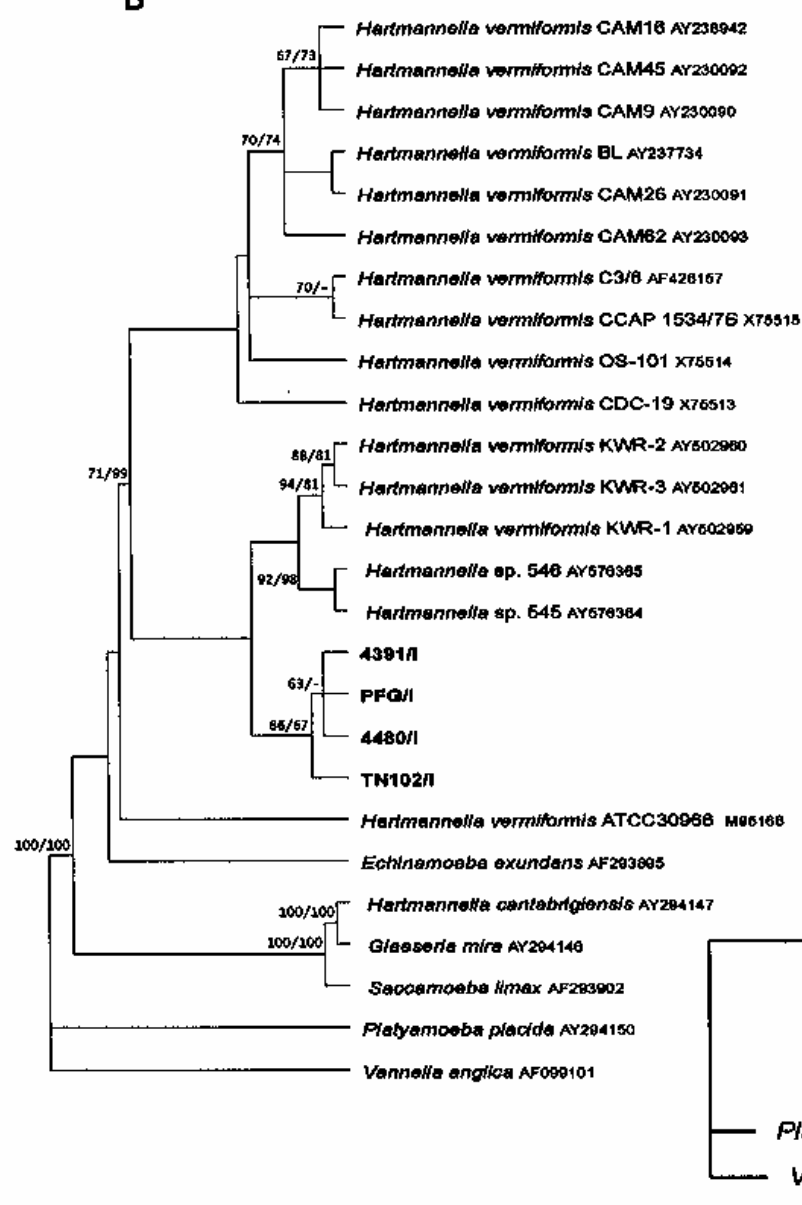

A

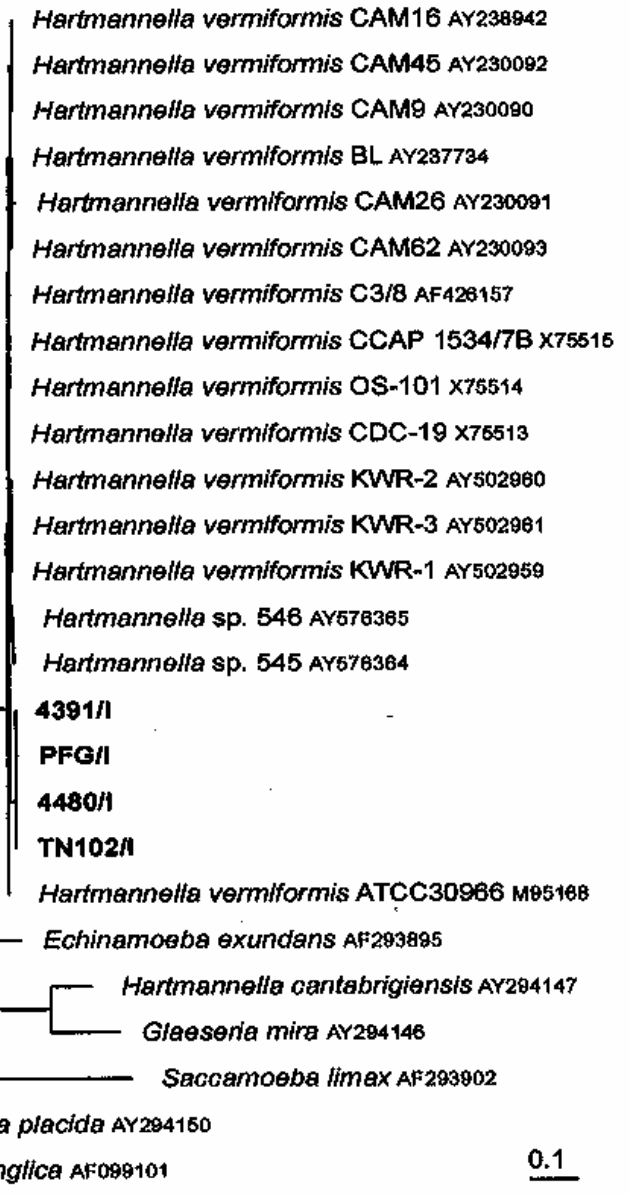

Fig. 19. Part A: Maximum-likelihood tree $(-\ln =10$ 426.647) of the SSU rRNA sequences. The distance scale is given under the tree. Part B: Topology of tree A. Bootstrap values are given for the nodes gaining more than $50 \%$ support. The sequences newly acquired and for the first time analysed are in bold.

identity with the eight complete $H$. vermiformis sequences retrieved from the GenBank is $97.70-98.80 \%$.

The total length of the alignment was 2,144 sites, from which 664 positions were parsimony informative. As seen from the topology of the ML tree (Fig. 19), fish-isolated strains clustered together with the $H$. vermiformis type strain (ATCC 30966), 13 environmental strains of $H$. vermiformis and two strains isolated from tadpoles. Extremely short tree branches indicated minimal differences among the 20 analysed sequences. Phylogenetic analyses revealed the monophyly of the fishisolated strains within the $H$. vermiformis clade. Only strict consensus of trees constructed using MP Ts:Tv = 1:1 did not support this monophyly. Echinamoeba exundans appeared as the closest relative of $H$. vermiformis while $H$. cantabrigiensis, the second sequenced species of the genus, branched separately from strains of $H$. vermiformis. This topology indicates the polyphyly of the genus Hartmannella.

\section{Fluorescence in situ hybridisation}

The species-specific probe designed in this study for $H$. vermiformis hybridised successfully with trophozoites of three clonal $H$. vermiformis cultures (4480/I, 4391/I and PFG/I) attached to slides, but not to trophozoites of Saccamoeba and Acanthamoeba species (clones LOS7N/I and P121/I). The same probe confirmed that histopathological lesions tested in this study (experimental infections with clone TN102/I, Fig. 20) were produced by the same amoeba species (Figs. 2123).

\section{DISCUSSION}

When trying to identify fish-isolated Hartmannella strains on the basis of their morphology, the lack of features discriminating individual species within the genus was a major problem. The extremely wide range of the length of locomotive forms was of no great diagnostic 


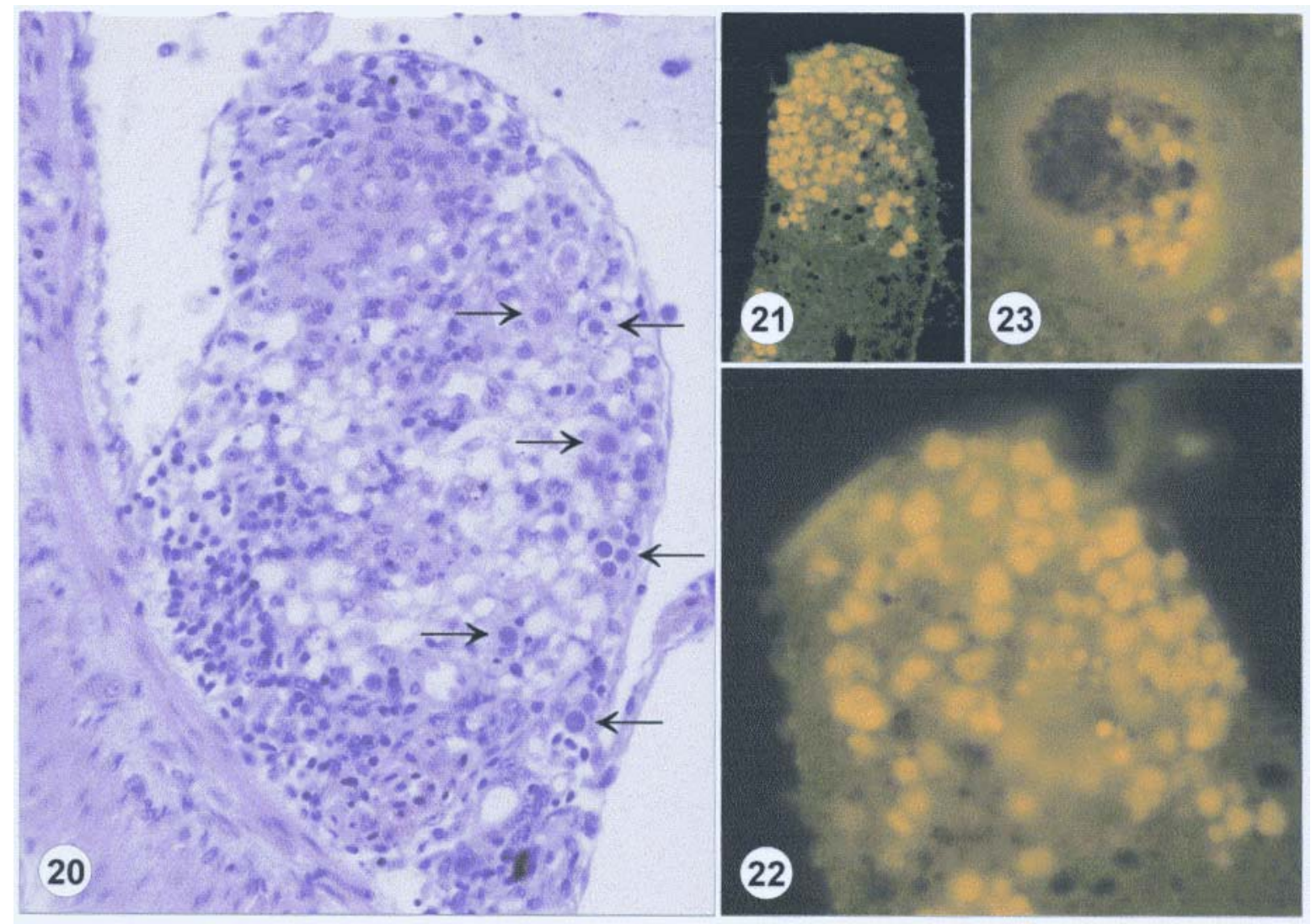

Fig. 20. Lesion caused by Hartmannella vermiformis (strain TN102) in experimentally infected Oreochromis niloticus. Amoebae are marked with arrows. H\&E, $\times 820$. Figs. 21, 22. Fluorescence in situ hybridisation of $H$. vermiformis in semiserial histological sections parallel to the control section shown in Fig. 20 (Fig. 21, $\times 380$; Fig. 22, $\times 980$ ). Fig. 23. Positively stained macrophages and remnants of $H$. vermiformis trophozoites in the granulomatous lesion $(\times 700)$.

value. A subsequent comparison of various strains by the author of H. vermiformis description (Page 1967) forced him to change his opinion on measurements, publishing new data in 1985. The locomotive forms of Hartmannella strains we have studied were even longer than those mentioned by Page (1985). Also, the median diameter of our cysts was greater than that given in Page's (1985) paper. Uroidal filaments used by Page to distinguish the genera Saccamoeba and Hartmannella were observed in trophozoites of our clonal cultures and documented by light and electron microscopy. While in the original description, Page (1967) indicated that "no uroidal filaments have ever been observed in $H$. vermiformis", in a generic revision (Page 1974) he mentioned that a few fine uroidal filaments were produced by adhesion in trophozoites. In a key to freshwater and soil gymnamoebae, Page (1988) distinguished Hartmannellidae from several other groups of amoebae, pointing out that adhesion uroids are typical of limax forms of Leptomyxidae, referring to uroidal knobs in Saccamoeba spp. The uroidal structures were not included in diagnostic features of Hartmannella spp. in the most recent monograph (Page 1991) on naked amoebae.
The taxonomic importance given to the fine structural sucker-like or cup-like surface formations at the level of the family Hartmannellidae (Page 1985) is surprising owing to their size and resolution attainable at a magnification of $\times 200000$. The documentation of these cell surface elements was not convincing in all published examples. Nevertheless, it was adopted as a taxonomically significant feature of the fine structure of Hartmannellidae in the most recent monograph (Page 1991) and is considered also in a phylogenetic study (Amaral Zettler 2000) to be evolutionary important. Smirnov (1996/1997) was the first to describe the cell surface coat of Hartmannella sp. without any visible differentiation. In our opinion, such delicate structures as these cup-like structures can be significantly influenced by the quality of fixation and the angle of sectioning. Difficulties in obtaining adequately fixed Hartmannella cultures were mentioned by Page (1985), who undoubtedly was an experienced specialist. The undulated surface of trophozoites and nuclear envelopes in images he published in 1985 exemplify these difficulties. 
The separation of the cyst wall into two layers was observed in the material of this study, but contrary to the opinion of Smirnov and Michel (1999), we could not consider it a strain-related feature. We have found both types of cyst walls (with closely apposed or partially separated layers) in cysts of the same clonal culture.

The ecological and medical importance of free-living amoebae, along with the necessity of their reliable identification and classification inspired initial studies of phylogenetic relationships with Hartmannella strains included (Gunderson and Sogin 1986, Sogin 1989, 1991). Weekers et al. (1994) were motivated by the (at that time unexpected) distant phylogenetic relationship of Acanthamoeba and Naegleria. To continue studies of SSU rRNA gene sequence phylogeny of amoebae, they surprisingly selected Hartmannella "because of its similarity with Acanthamoeba in morphology and life cycle" and analysed four strains of different origin (UK, USA and Germany). Walochnik et al. (2002) expanded the set of analysed strains by one and found no correlation between the geographical origin of the strains and their phylogenetic relatedness. The presented results confirm this conclusion.

The exact diagnosis of Hartmannella species has increased in importance because of discoveries of new pathogens hosted by $H$. vermiformis (Horn et al. 2000, Bomhard et al. 2002) and due to isolations of amphizoic strains. In addition to our fish-isolated strains, there were only two Hartmannella strains isolated from aquatic organisms in the set of data available for comparison. All other strains were of the environmental type, isolated from drinking water biofilms, hospital water networks and sediments of a water reservoir or soil.

In addition to the search for molecular support of the diagnosis based on morphological features, this study has also attempted to place those Hartmannella species, of which sequences were available, within a phylogenetic context. Two strains isolated in 1964 and used by Page for his description of $H$. vermiformis were not declared explicitly type strains in the original paper (Page 1967), nevertheless according to the data available in the literature, they can be traced to two culture collections. There are CCAP1534/7A and CCAP1534/12 strains at the UK National Culture Collection (UKNCC) and ATCC30966 at the American Type Culture Collection (ATCC). The latter is identical with CCAP1534/12, being donated to the depositor (W. Balamuth) by F.C. Page.

The strange, unexpected phylogenetic position of Echinamoeba exundans interfering with branching pattern of representatives of two well-described, morphologically similar species of the genus Hartmannella $(H$. cantabrigiensis and $H$. vermiformis) deserve further study. The same sequence (AF293895), designated as belonging to Echinamoeba exundans, was used in several phylogenetic studies. Amaral Zettler et al. (2000) included it together with one unspecified $H$. vermiformis sequence in the study focused on the phylogeny of leptomyxid amoebae. They stressed the close relationship between both taxa and elaborated the hypothesis that Echinamoeba morphology evolved relatively recently from a Hartmannella-like ancestor. In the same study, thermotolerance was pointed out in species of both genera (Echinamoeba and Hartmannella). This applies to Echinamoeba strain SH274 listed on the ATCC as ATCC50171. This strain was isolated from a hot-water tank (California, 1987) and cultured at $25^{\circ} \mathrm{C}$ to $35^{\circ} \mathrm{C}$. The thermotolerance mentioned as typical of species of the genus Hartmannella, has been deduced from the study by Fields et al. (1989). This study was focused on the intracellular multiplication of Legionella pneumophila in amoebae isolated from hospital hot-water tanks. Although Fields et al. (1989) mentioned temperatures reaching $52^{\circ} \mathrm{C}$, ATCC Hartmannella strains, including one deposited originally as $H$. thermophila (strain LCD1A), are cultured at $25^{\circ} \mathrm{C}$. The culturing experiments made by Kadlec (1978) with several Hartmannella vermiformis strains isolated from domestic animals showed that amoebae adapted to room temperatures degenerate upon prolonged culturing at $37^{\circ} \mathrm{C}$. The extreme high temperature tolerance was proved in four Hartmannella strains isolated from hot-water systems by culturing them at $53^{\circ} \mathrm{C}$ (Rohr et al. 1998). Among the four fishisolated strains tested in three consecutive passages for the tolerance of temperatures higher than that routinely used, three (4391, PFG and TN102) grew very well at $37^{\circ} \mathrm{C}$ and two (4391 and $\mathrm{PFG}$ ) even at $42^{\circ} \mathrm{C}$, while strain 4480 was culturable at $20^{\circ} \mathrm{C}$ only.

In the context with the history of $E$. exundans description and the results of our phylogenetic analyses, the diagnosis of the strain SH274 (ATCC50171), to which SSU rRNA gene sequence AF293895 belongs, should be verified. The species was originally described within the genus Hartmannella from a single strain isolated from material collected from a city lake in Tuskegee, Alabama in 1965 (Page 1967). Not all reasons for transfer of this species to the newly established genus Echinamoeba Page, 1975 are clear from published data. It seems that contrary to the Hartmannella exundans description (Page 1967), a greater importance was placed later on the occurrence of flabellate and irregular trophozoites with fine subpseudopodia, than on limaxlike forms described as common in $H$. exundans. Such forms were considered analogous to a second species of this genus (E. silvestris). In our experience, under standard conditions of observations, a small proportion of trophozoites of Echinamoeba-like morphotype can be seen also in clonal cultures of $H$. vermiformis. We have related this phenomenon to the condition of individual cells. Since the sequence of the type strain (deposited now in the UKNCC as E. exundans CCAP1534/4) is not available, the conclusions on the phylogeny of Echin- 
amoeba spp. should be guarded and polyphyly of the genus Hartmannella verified.

Grimm et al. (2001), who were interested in the identification of Hartmannella and Naegleria in Legionellapositive environmental samples, generated the Hart 498 probe and declared it as genus specific. The design of their probe was influenced by the fact that the sequence of $H$. cantabrigiensis was not available then. Now it is clear that they have generated an oligonucleotide probe for $H$. vermiformis. It is $18 \mathrm{bp}$ long, which is seven nucleotides shorter than our probe. There is also a difference in the selected segment of the SSU rRNA gene sequence. Although in situ hybridisation provided a strong signal of amoebae within host tissues tested in our experiments, not all control procedures required for specificity of the probe (e.g., test with $H$. cantabrigiensis) could be applied. Fish pathology can only benefit from direct diagnostic methods. Thus an in situ hybridisation probe is a promising tool for the detection of $H$. vermiformis in histopathological lesions and deserves further screening.

Acknowledgements. This study was supported by the Grant Agency of the Academy of Sciences of the Czech Republic (project no. A6022202), research project of the Institute of Parasitology, Academy of Sciences of the Czech Republic (Z60220518) and by Ministry of Education, Youth and Sports (project no. MSM 6007665801).

\section{REFERENCES}

AITKEN D., HAY J., KINNEAR F.B., KIRKNESS C.M. LEE W.R., SEAL D.V. 1996: Amebic keratitis in a wearer of disposable contact lenses due to a mixed Vahlkampfia and Hartmannella infection. Ophthalmology 103: 485494.

AMARAL ZETTLER L.A., NERAD T.A., O'KELLY C.J., PEGLAR M.T., GILLEVET P.M., SILBERMAN J.D., SOGIN M.L. 2000: A molecular reassessment of the leptomyxid amoebae. Protist 151: 275-282.

BARTA J.R., MARTIN D.S., LIBERATOR P.A., DASHKEWITZ M., ANDERSON J.W., DEIGHNER S.D., ELBRECHT A., PERKINS-BARROW A., JENKINS M.C., DANFORTH H.D., RUFF M.D., PROFOUS-JUCHELKA H. 1997: Phylogenetic relationships among eight Eimeria species infecting domestic fowl inferred using complete small subunit ribosomal DNA sequences. J. Parasitol. 83: 262-271.

BOMHARD W. von, POSPISCHIL A., RICHTER M., KAPS S., POLKINGHORNE A., ZIMMERMANN D.R. 2002: Amoebic infections in cats with ocular disease? Vet. Rec. 150: 556.

BRIELAND J., McCLAIN M., HEATH L., CHRISP C., HUFFNAGLE G., LEGENDRE M., HURLEY M., FANTONE J., ENGLEBER G.C. 1996: Coinoculation with Hartmannella vermiformis enhances replicative Legionella pneumophila lung infection in a murine model of legionaires disease. Infect. Immun. 64: 2449-2456.

De JONCKHEERE J.F., BROWN S. 1998: Is the free-living amoeba Hartmannella causing keratitis? Clin. Infect. 36: 349-350.

De JONCKHEERE J.F., BROWN S. 1999: Non-Acanthamoeba amoebic keratitis. Cornea 18: 499-501.

DYKOVÁ I., LOM J. 2004: Advances in the knowledge of amphizoic amoebae infecting fish. Folia Parasitol. 51: 8197.

DYKOVÁ I., MACHÁČKOVÁ B., PECKOVÁ H. 1997 : Amoebae isolated from organs of farmed tilapias, Oreochromis niloticus. Folia Parasitol. 44: 81-90.

DYKSTRA M.J. 1993: A Manual of Applied Techniques for Biological Electron Microscopy. Plenum Press, New York and London, $257 \mathrm{pp}$.
ETTINGER M.R., WEBB S.R., HARRIS S.A., McININCH S.P., GARMAN G.C., BROWN B.L. 2002: Distribution of free-living amoebae in James River, Virginia, USA. Parasitol. Res. 89: 6-15.

FIELDS B.S. 1996: The molecular ecology of legionellae. Trends Microbiol. 4: 286-290.

FIELDS B.S., SANDEN G.S., BARBAREE J.M., MORRILL W.E., WADOWSKY R.M., WHITE E.H., FEELY J.C. 1989: Intracellular multiplication of Legionella pneumophila in amoebae isolated from hospital hot water tanks. Curr. Microbiol. 18: 131-137.

GRIMM D., LUDWIG W., BRANDT B.C., MICHEL R., SCHLEIFER K.-H., HACKER J., STEINERT M. 2001: Development of $18 \mathrm{~S}$ rRNA-targeted oligonucleotide probes for specific detection of Hartmannella and Naegleria in Legionella-positive environmental samples. Syst. Appl. Microbiol. 24: 76-82.

GUNDERSON J.H., SOGIN M.L. 1986: Length variation in eukaryotic rRNAs: small subunit rRNAs from the protists Acanthamoeba castellani and Euglena gracilis. Gene 44: 63-70.

HALL T.A. 1999: BioEdit: a user-friendly biological sequence alignment editor and analysis program for Windows 95/98/NT. Nucl. Acids Symp. 41: 95-98.

HORN M., WAGNER M., MÜLLER K.-D., SCHMID E.R., FRITSCHE T.R., SCHLEIFER K.-H., MICHEL R. 2000: Neochlamydia hartmannellae gen. nov., sp. nov. (Parachlamydiaceae), an endoparasite of the amoeba Hartmannella vermiformis. Microbiology 146: 1231-1239.

INOUE T., ASARI S., TAHARA K., HAYASHI K., KIRITOSHI A., SHIMOMURA Y. 1998: Acanthamoeba keratitis with symbiosis of Hartmannella amoeba. Am. J. Ophthalmol. 125: 721-723.

KADLEC V. 1978: The occurrence of amphizoic amoebae in domestic animals. J. Protozool. 25: 235-237.

KINNEAR F.B. 2003: Cytopathogenicity of Acanthamoeba, Vahlkampfia and Hartmannella: quantitative \& qualitative in vitro studies on keratocytes. J. Infect. 46: 228-237.

KOMMINOTH P. 1996: Detection of mRNA in tissue sections using DIG-labelled RNA and oligonucleotide probes. In: S. Grunewald-Jahho, J. Kessey, M. Leous, R. van 
Miltenberg and C. Schroeder (Eds.), Non-radioactive in situ Hybridisation Application Manual. Boehringer Mannheim GmbH, Biochemica, pp. 126-131.

KUCHTA J.M., NAVRATIL J.S., SHEPHERD M.E., WADOWSKY R.M., DOWLING J.N., STATES S.J., YEE R.B. 1993: Impact of chlorine and heat on the survival of Hartmannella vermiformis and subsequent growth of Legionella pneumophila. Appl. Environ. Microbiol. 59: 4096-4100.

PAGE F.C. 1967: Taxonomic criteria for limax amoebae, with description of 3 new species of Hartmannella and 3 of Vahlkampfia. J. Protozool. 14: 499-521.

PAGE F.C. 1974: A further study of taxonomic criteria for limax amoebae, with descriptions of new species and key to genera. Arch. Protistenkd. 116: 149-184.

PAGE F.C. 1985: The limax amoebae: comparative fine structure of the Hartmannellidae (Lobosea) and further comparisons with the Vahlkampfiidae (Heterolobosea). Protistologica 21: 361-383.

PAGE F.C. 1988: A New Key to Freshwater and Soil Gymnamoebae. Freshwater Biological Association, Ambleside, Cumbria, 122 pp.

PAGE F.C. 1991: Nackte Rhizopoda. In: F.C. Page and F.J. Siemensma: Nackte Rhizopoda und Heliozoea. Gustav Fischer Verlag, Stuttgart, New York, pp. 1-170.

POSADA D., CRANDALL K.A. 1998: Modeltest: testing the model of DNA substitution. Bioinformatics 14: 817-818.

ROHR U., WEBER S., MICHEL R., SELENKA F., WILHELM M. 1998: Comparison of free-living amoebae in hot water systems of hospitals with isolates from moist sanitary areas by identifying genera and determining temperature tolerance. Appl. Environ. Microbiol. 64: 182184.

SMIRNOV A.V. 1996/1997: Two new species of marine amoebae: Hartmannella lobifera $\mathrm{n}$. sp. and Korotnevella nivo n. sp. (Lobosea, Gymnamoebia). Arch. Protistenkd. 147: 283-292.

SMIRNOV A.V. 2002: Vertical distribution and abundance of gymnamoebae (Rhizopoda) in bottom sediments of the brackish-water Niva Bay (Baltic Sea, the Sound). Protist 153: $238-250$.
SMIRNOV A.V., GOODKOV A.V. 1995: Systematic diversity of gymnamoebae (Lobosea) in the bottom sediments of a freshwater lake. Zoosyst. Ross. 4: 201-203.

SMIRNOV A.V., MICHEL R. 1999: New data on the cyst structure of Hartmannella vermiformis Page, 1967 (Lobosea, Gymnamoebia). Protistology 1: 82-85.

SOGIN M.L. 1989: Evolution of eukaryotic microorganisms and their small subunit ribosomal RNAs. Am. Zool. 29: 487-499.

SOGIN M.L. 1991: The phylogenetic significance of sequence diversity and length variation in eukaryotic small subunit ribosomal RNA coding regions. In: L. Waren and H. Koprowski (Eds.), New Perspectives on Evolution. WileyLiss, New York, pp. 175-188.

SWOFFORD D.L. 1999: PAUP*: Phylogenetic Analysis Using Parsimony, Version 4.0b8a. Sinauer Associates, Sunderland, MA.

TELFORD S.R., BURSEY C.R. 2003: Comparative parasitology of squamate reptiles endemic to scrub and sandhills communities of North-central Florida, USA. Comp. Parasitol. 70: 172-181.

THOMPSON J.D., GIBSON T.J., PLEWNIAK F., JEANMOUGIN F., HIGGINS D.G. 1997: The CLUSTAL X windows interface: flexible strategies for multiple sequence alignment aided by quality analysis tools. Nucl. Acids Res. 25: 4876-4882.

TRAUT W., SAHARA K., OTTO T.D., MAREC F. 1999: Molecular differentiation of sex chromosomes probed by comparative genomic hybridization. Chromosoma 108: 173-180.

WALOCHNIK J., MICHEL R., ASPÖK H. 2002: Discrepancy between morphological and molecular biological characters in a strain of Hartmannella vermiformis Page, 1967 (Lobosea, Gymnamoebia). Protistology 2: 185-188.

WEEKERS P.H.H., GAST R.J., FUERST P.A., BYERS T.J. 1994: Sequence variations in small-subunit ribosomal RNAs of Hartmannella vermiformis and their phylogenetic implications. Mol. Biol. Evol. 11: 684-690.

YOUNG W.S. 1994: In situ hybridization with oligodeoxyribonucleotide probes. In: D.G. Wilkinson (Ed.), In situ Hybridization. A Practical Approach. Oxford University Press, pp. 33-44.

Accepted 15 July 2005 